\title{
PRICE AND PERFORMANCE TRENDS FOR CELLULAR TRAIL CAMERAS EXPLAINED WITH A TIME TREND, GOOGLE KEYWORD TRENDS, AND A USE CASE OF SUBURBAN DEER MANAGEMENT
}

\author{
G. Kent Webb, San Jose State University, g.webb@sjsu.edu
}

\begin{abstract}
Price and performance improvements for trail cameras, remote cameras designed for wildlife observation, have given wildlife researchers a widely accepted new tool. After their introduction in 2010, cellular trail cameras have become popular, saving travel time and reducing disturbance to wildlife. A use case of trail cameras for suburban deer management illustrates desirable product features and risks of using citizen science for research. A time trend of camera prices identifies a common product price pattern for technology products, a decline following a logistic or inverted s-curve. Data from Google Keyword Trends captures the changing level of market interest correlated with high statistical significance compared to price and corresponding to performance improvements thus providing evidence of the usefulness of the Google Trends data for project management and systems analysis.
\end{abstract}

Keywords: Mobile Technology, Business Intelligence, Technology Forecast, Internet of Things

\section{INTRODUCTION}

Wildlife managers have always faced challenges to data collection given that their subjects often live in inaccessible areas, move to avoid detection, and are often sparsely distributed across wide geographic areas. With strong demand for inexpensive camera and communications components in large markets such as cell phones and surveillance cameras, innovation and scale economies have resulted in dramatic prices declines and performance improvements for components also used in trail cameras. Companies have combined these components with special features such as camouflaged housing to provide trail cameras which can be used, as the name suggests, on the trail in the great outdoors. Typical use involves placing a trail camera with batteries and motion sensing in a remote location to observe wildlife. Deer hunting is the primary market, but all the trail camera markets together would not be sufficient to support the economies of scale and research required to develop the camera and communications components which are adapted from surveillance and other larger markets. For wildlife researchers and managers, trail cameras provide much detail about behavior with minimal disturbance. The following short history of trail cameras and a use case of trail cameras in a suburban deer research project provide a framework for understanding factors driving product developments.

\section{History of Trail Cameras}

George Shiras III is often cited as the inventor of the trail camera in the 1880s. It was a large device that relied on trip wires connected to a baited trip that set off the camera and a flash of magnesium that startled the deer who were the targets of his photography. Long, MacKay, Ray, and Zielinski (2012) provide a detailed history of trail cameras in their book on noninvasive wildlife survey methods. They note that photographs from trail cameras became popular when they appeared in National Geographic magazine around 1906. A small market for wildlife photography was created. By the 1960s camera systems weights were reduced to 47 pounds (p. 110). For years, wildlife researchers generally considered trail cameras impractical because of weight and cost, including the effort to support the systems. A few companies continued to develop products for these small markets. Cameras were improved with infrared lighting for night pictures and video, motion sensing replacing trip wires, batteries to provide power, better imaging technology, and they now weigh about a pound or less. Camera resolution, measured in megapixels, is a key feature distinguishing camera models with dramatic increases in recent decades.

In the late 1980s, cost, size, and performance were improved enough to attract deer hunters who put cameras out to detect the location of trophy bucks they could hunt during the deer season. This market was substantially larger than wildlife photography, attracting more revenue and new companies. Hunters often placed these cameras in 
distant or difficult to access locations, which could require a significant investment in time to retrieve images. In addition, frequent visits to the cameras disturbed the deer. A target deer might decide to move elsewhere. Therefore, the cellular trail camera was introduced in 2010.

The ScoutGuard SG580M (M for mobile) was introduced on August 11, 2010, featuring a 5 megapixel camera using CMOS sensors and motion detection, infrared lights, SD card support up to 16 gigabytes and the ability to send images using the cellular network with multimedia messaging or email. The camera was compact, waterproof, and powered by $8 \mathrm{AA}$ batteries. It required a setup fee and monthly subscription to a cellular network. One drawback was that the added power consumption of the cellular components significantly reduced battery life, by about half depending on use.

As illustrated in Figure 1, the ScoutGuard 580M, the original cellular trail camera, was available on Amazon throughout the time period of August, 2010 to April 2020. After several years the camera was sold as new by third parties and listed as HCO SG 580M. The camera was upgraded to be compatible for new generations of cellular technology, but the product was recently discontinued. A higher resolution ScoutGuard, the 550M, was introduced in 2011 at the higher price shown on Figure 1. The price for this camera came from an old B\&H Photo catalog found on the internet, so only one data point is available, but it shows the process of introducing a new product with improved specifications, in this case an eight-megapixel camera improved from five megapixels

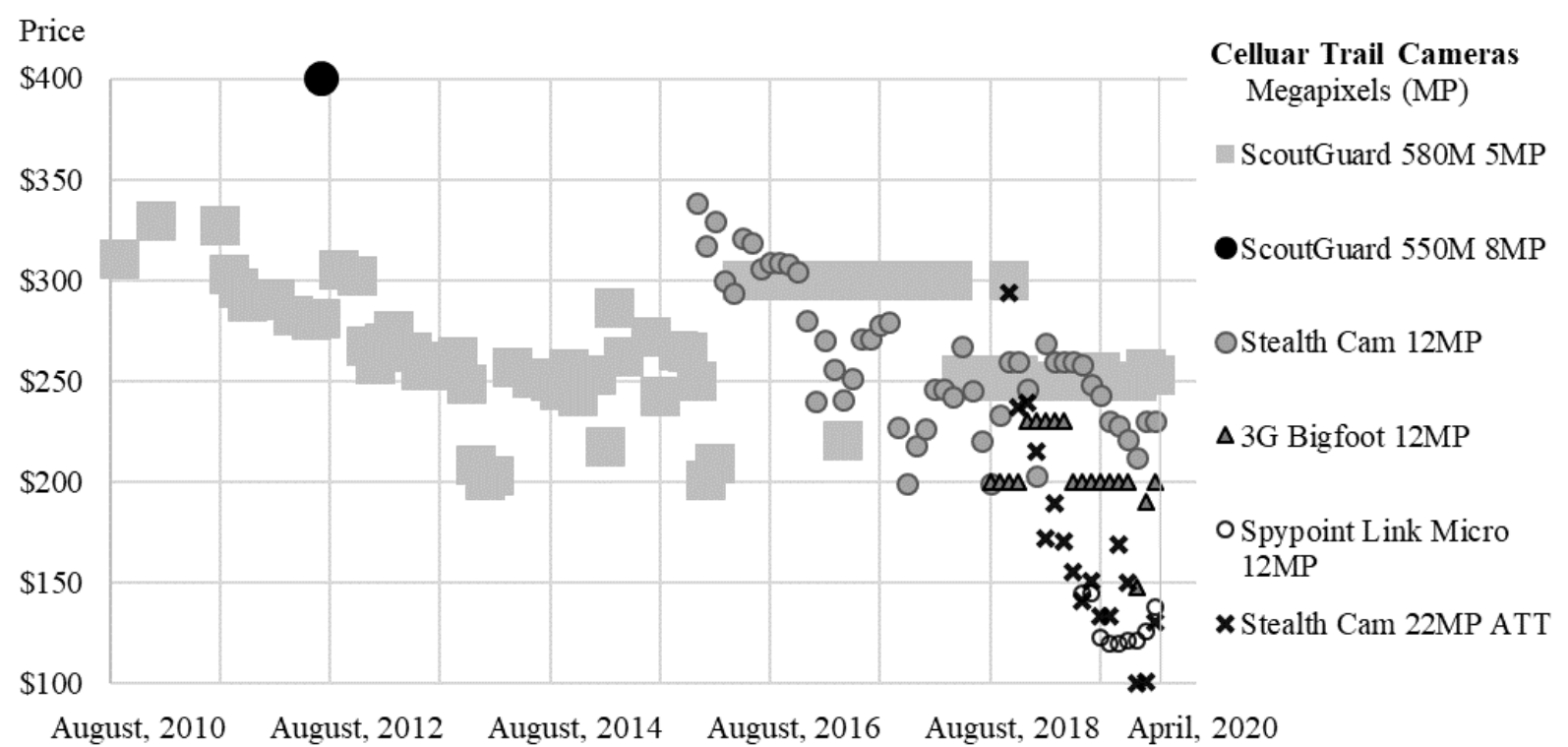

Figure 1: Prices listed on Amazon.com for cellular trail cameras. Data extracted from CamelCamelCamel.com charts and an old B\&H Photo catalog for the ScoutGuard 550M.

As data from Google Trends will show, cellular cameras were something of a novelty until about 2016 when interest significantly escalated. The increased potential market attracted new companies, significant product improvements, and lower prices. The decline in prices over time for the first cellular camera, the gray boxes in Figure 1, accelerated for new cameras entering a more competitive market. Pricing for the first camera then fluctuated, sometimes increasing substantially, a common pattern for legacy technology products, which will be discussed more in a following section. The next section gives an example of how trail cameras are used for research and the product characteristics that generate demand for cellular trail cameras, providing a framework for the empirical analysis.

\section{A Use Case of Suburban Deer Management}

A retirement community, the Villages in San Jose, California, filed a request to cull suburban deer because of damage to landscaping. After public debate, a doe sterilization project was approved by the state, which started in 2013. All does were sterilized, although the goal was not complete elimination of the deer. It was assumed new 


\section{Issues in Information Systems}

Volume 21, Issue 2, pp. 196-205, 2020

deer would migrate into the community, but after three years of no confirmed sightings of new deer and with no fawns to replaced deceased deer, the population appeared to be heading toward zero. A trail camera project was initiated to investigate the migration problem and find some solutions with a goal of installing cellular trail cameras to provide real-time imagery.

As a test, the first cameras deployed were basic trail cameras with motion sensing, costing about $\$ 100$, and using eight AA batteries for power that lasted for two to four weeks, depending on camera activity. Camera life is generally much longer in typical trail camera terrain, but some cameras were set in areas with high activity, much of it not related to deer. A significant amount of time was spent sorting through imagery of cars, people, and dogs. Sometimes wind triggered the cameras. Cellular cameras required a network subscription based on the amount of data transmitted. Given that this was a volunteer project, it was determined that cell cameras would be too expensive because transmission rates would be high given the amount of irrelevant images capture by the cameras.

Regular security cameras had been used at another location for some imaging, but in this location there was no power or wired network available in the areas of interest. Experiments with some wireless products using WiFi and solar determined that they were unreliable. WiFi and solar reliability improved over the course of this project that lasted three years.

As the project developed, cameras were used to investigate areas where fencing might be modified to safely allow some deer to enter from the undeveloped area outside the community. Figure 2 shows an image of a doe jumping through a fence opening designed to allow deer to enter but to keep feral hogs out because they were dangerous and very destruction to landscaping. The cameras verified that the fence design worked well, allowing deer to enter but feral hogs were unable to make the jump. A few new deer entered, but none stayed.

Trail cameras were also deployed in an undeveloped area outside the community to observe deer behavior. Given the amount of time required to access these more distant cameras, cellular cameras were also considered with funding being the major barrier. Discussions of using cellular or other wireless approaches to monitor these areas continued throughout the project.

Late in the project a new camera product became available, an outdoor WiFi security camera using IP that could send images via email and had a built-in storage

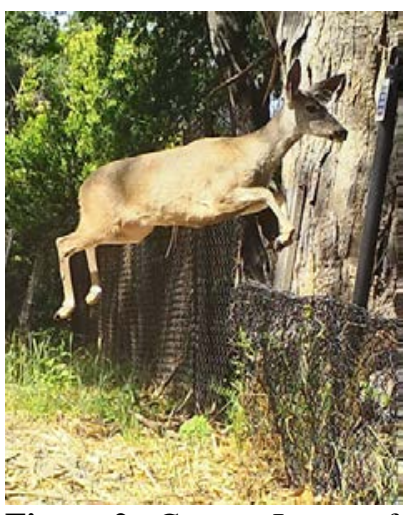

Figure 2: Camera Image of Doe Jumping Through a

Fence Opening Designed to Keep Feral Hogs Out battery and solar power. The camera was tested and seemed promising. The community became interested in using the cameras for safety related to hikers in the undeveloped area and as early warning for fire. A budget for the project became available so it appeared that WiFi cameras could be deployed in high traffic areas where WiFi was available and cellular trail cameras could be deployed at the more remote areas.

Instead, the camera project was terminated when some community administrators decided that deploying cameras for safety created a potential liability for the community if something happened related to safety that was not prevented by the cameras. Signs with the phrase "cameras are here for your safety" had been posted near some of the trail cameras used to monitor the deer, including the one monitoring the fence opening which took the photo in Figure 2.

The decision to remove the cameras came at a critical time for the research project since a fawn had been sited in the community and it was unclear whether this was from migration or a birth from one of the sterilized does. Migration was the fundamental issue of this research project. It appeared that three years of work would be forfeited because some participants attributed the fawn to a doe that had migrated into the community undetected by the cameras. Fortunately, a photo by a resident showed the fawn was with a doe that was lactating, clear evidence that the fawn came from a sterilized doe. Sterilization is close to, but not 100 percent effective. In this case, 2 of 105 sterilized does gave birth. The first birth had been well documented by the cameras.

Webb (2017) provides more detail about this project and the decline of this suburban deer population. There are only a few experiments of this type and this one provided strong evidence for the effectiveness of non-lethal deer 


\section{Issues in Information Systems}

Volume 21, Issue 2, pp. 196-205, 2020

population control. The few other communities that have taken this approach have actively shared their data to support research and build information to support best practices for suburban deer management. After the loss of the key supporter of this project, the general attitude drifted into a reluctance to share data or cooperate. Although the primary researcher that conducted the sterilization, White Buffalo, did so as part of an officially sanctioned experiment by the California Department of Fish and Wildlife, it remains to be seen if the community will cooperate with White Buffalo by collecting and reporting the data or if the state will compel them to cooperate. Wildlife agencies have been reluctant to support non-lethal management of deer because many perceive the approach to be a threat to one of their primary revenue sources, deer hunting (Kirkpatrick and Turner, 2020). At first, the deer population counts that were the primary measure of the overall success of the project had been done by the primary researcher, but to save money the community organized their own count - a citizen science approach.

During the camera project seven or eight trail cameras were deployed at any time. For the first two years of the project, cameras were visited every week to change batteries and recover images from the SD cards. During the last year cameras were visited every two weeks. Travel and camera maintenance required about 6 hours for each visit. Manually inspecting the saved images to find useful information required about 8 hours per visit and was not 100 percent reliable. These older trail cameras provided a representative image for videos that were typically 30 seconds long, but often they did not capture the deer that were the target, so some information was lost.

New cellular trail cameras with built-in artificial intelligence that identify deer can dramatically reduce the amount of imagery that would need to be transmitted and reviewed. The need to visit the cameras to replace batteries has also been significantly reduced with improved solar power and battery technology. Use of cameras has become so popular among wildlife researchers that there are a number of efforts to apply and advance artificial intelligence to improve camera effectiveness [Gonzalez, Montes, Puig, Johnson, Mengersen \& Gatson, 2016; Green, Rees, Stephens, Hill \& Giordano, 2020; Pagany \& Dorner, 2019; Terada, Ohno, Mukai, Ishibashi \& Yokotani, 2019].

\section{Cameras and the Internet of Things (IoT)}

As the case example suggests, wired cameras are best for real-time images when cables and power are readily available, usually in high human population density areas. Wireless IP cameras can work well when WiFi and adequate power is available. Cellular cameras are best in areas with cellular coverage and the absence of WiFi or other internet access. Some idea of the current size of these areas can be seen by comparing Xfinity's WiFi coverage map and Verizon's cellular coverage map. Still, that leaves a large rural area where wildlife is often located that cannot, as of this writing, be served except for limited and expensive satellite access. Nazir (2017) discusses technical approaches to the problems of remote power and limited bandwidth for wildlife monitoring using satellites. However, a new generation of satellites has been launched by SpaceX that will provide lower prices for internet access with smaller equipment that will make this approach more feasible in areas not currently served by terrestrial internet.

Akyildiz and Kak (2019) describe how this satellite approach will bring global IoT connectivity at low costs. In their paper visualizing the future IoT, Gubbi, Buyya, Marusic and Palaniswami (2013) note that the backbone may vary between cellular, WiFi, and satellite and that cameras are the most widely used network application for surveillance. Elias, Golubovic, Krintz and Wolski (2017) discuss the future of wildlife research with the combination of IoT, cameras, and image processing.

\section{Forecasting Technology for System Analysis and Project Management}

In our use case for camera deployment, we relied on Amazon product searches to study what new camera technologies were becoming available and how their costs were changing. Forecasting the price and performance of available technology is a common issue in systems design and project management. Smith, Collins, and Mavris (2017) survey forecasting approaches used to evaluate emerging technologies in systems design and provide a guide to help the decision maker choose the best approach. Haleem, Mannan, Luthra, Kumar and Khurana (2019) also provide an overview of technology forecasting approaches and best practices. Flam (2004) uses patterns for the price and performance of semiconductors to make predictions about future products. Such predictions can helpful in designing new products or applications as part of a feasibility analysis. Gargallo and Gorriz (2007) discuss some of the problems involved in measuring communications technology performance. For cameras, resolution measured in 
megapixels provides one clear quantitative measure of performance. Battery life, camera speed, and camera range are other major factors with quantifiable performance characteristics.

Webb (2010) proposed a price and performance frontier evolving for computer components, with new components introduced at higher prices while production was low, falling during market acceptance, then often rising again with product obsolescence and limited demand for legacy hardware. Overlaying each product price curve produces a price/performance frontier of the lowest priced product. As discussed in the article, an explanation for the rapid price reductions for semiconductor components has been famously described as Moore's law with a doubling of transistor density every year or two, allowing for scale economies and rapid price declines. Moore's law is also discussed in Flamm (2004). Much earlier, in 1936, T.J. Wright wrote about a similar pattern of cost declines affecting the cost of airplanes. As to pricing based on these declining cost curves, experience and the data for camera prices in Figure 1 show that prices often linger at the high starting price during the market introduction phase and may rise in the legacy buying phase.

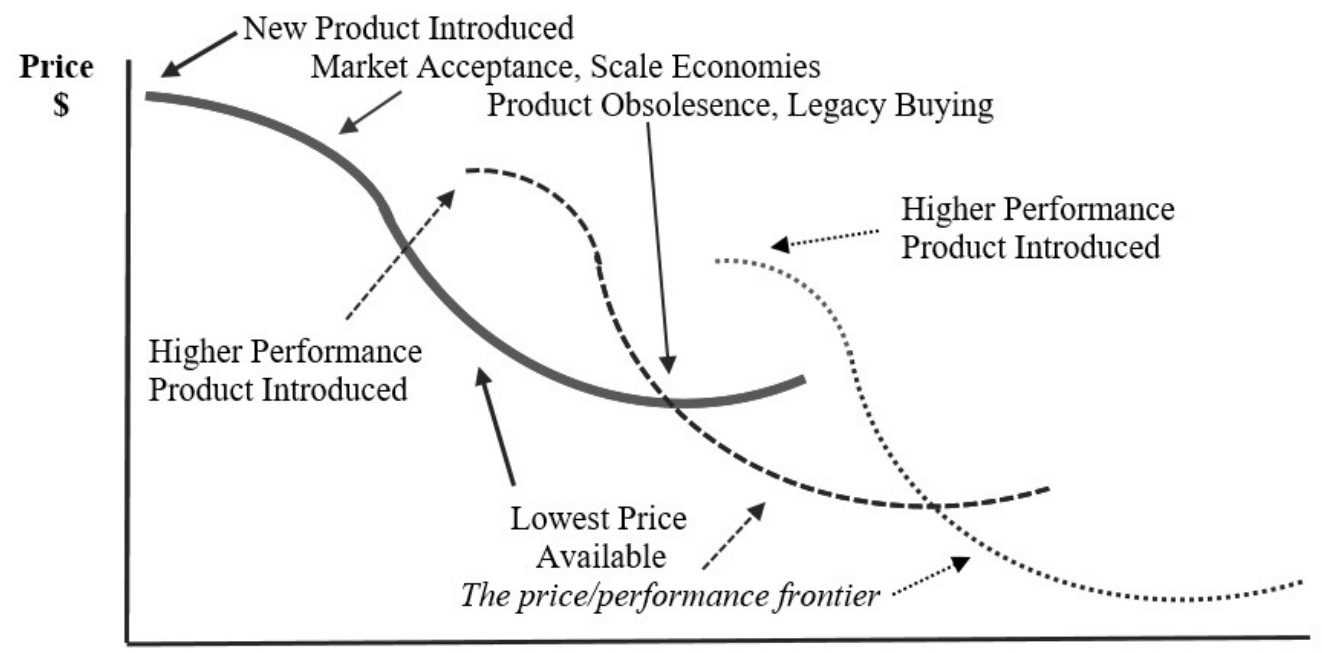

Time

Figure 3: A hypothetical framework for how price and performance of new technology products change over time.

Figure 3 illustrates the theory. Products are introduced at a high price for first adopters willing to pay for high performance. If the product is accepted, scale economies allow rapid price declines. As newer, higher performance products are introduced and scale economies allow for lower prices, older products are displaced but some demand continues as legacy purchases. Prices often increase during this period because of various compatibility issues with existing equipment or user inertia, reluctance to change from a well understood product. As suggested by Figure 3, the "Product Obsolesence, Legacy Buying" phase begins when the price of a higher performance product crosses below the older, legacy model. As illustrated in the figure, the "price/performance frontier" is the lowest price for equipment at any time.

As newer, higher performance products are introduced, scale economies related to the components of the technology equipment allow for lower prices. As an example of this, Webb (1997) explains how economies of scale allow each new generation of semiconductors products to offer higher performance at lower prices. A comparison of the hypothetical framework in Figure 3 with the actual price data in Figure 1 suggests the pattern is at work in the cellular trail camera market. This hypothetical is tested and confirmed as $\mathrm{H}_{1}$ and $\mathrm{H}_{2}$ in the next section.

Also tested as $\mathrm{H}_{3}$ is the usefulness of Google Keyword Trends data for technology forecasting. The Google Trends data is freely available as an index of search activity for keywords in Google's search engine. Data may be available back to 2004, depending keyword search volume. There have been several studies done using Google Trends as an input to a forecasting effort. Manrique, Qi, Morgenstern, Velásquez, Lu and Johnson (2013) use it in an example of a big data approach to forecasting civil unrest. Webb (2009) applies Google Trends to estimate home foreclosures. Jun, Yoo, and Choi (2018) summarize ten years of research on big data applications with Google Trends data, noting 


\section{Issues in Information Systems}

Volume 21, Issue 2, pp. 196-205, 2020

that application emphasis is shifting from analysis to forecasting. Duwe, Herrmann and Spath (2018) show Google Trends could have been used to make reliable forecasts of historic technology product innovations. Chumnumpan and Shi (2019) use Google Trends to forecast market diffusion for new technology products, the iPhone and iPad.

Regressing Google Trends data for cellular trail cameras against the lowest camera price data shows a strong statistical correlation. As a forecasting tool, the Google Trends data also gives a statistically significant estimation of the price six or twelve months ahead. In practice, a project manager or systems analyst may find a data visualization approach to be helpful when making a deployment decision given that the equations validate the applicability of the data. A common goal in these decisions is to avoid adopting technologies that will not be accepted by the market resulting in higher prices, less improvement, and potential obsolescence.

\section{RESEARCH METHODOLOGY}

The research presented here focuses on an approach to developing information that can help the systems analyst or project manager evaluate the prospects for a new technology. Data on cellular trail camera prices used in the statistical analysis came from CamelCamelCamel.com, as reported earlier in Figure 1. The company tracks products sold on Amazon, providing a graphical history and an alert feature so that someone looking for the product can see how prices have changed over time and receive an email alert when a good price is available. The data used here was created by searching the site for all cellular trail cameras and collection data for cameras that had some extensive history. Since the data were presented in chart form without the underlying numbers, a very well designed tool (WebPlotDigitizer) was used to convert the charts to numbers. An internet search of historical data was also conducted, but no time series could be developed. Search interest data came from Google Trends, a free tool that provides indexed, time series data on Google searches for keywords. Data can be downloaded in csv format.

The first and second research hypotheses, listed below, addresses how prices change over time. Camera prices in this analysis are indexed to 1 for the starting price, with other prices measured as a proportion of the introductory price. For example, a camera introduced for $\$ 200$ that falls to $\$ 100$ is represented as $0.5\left(\mathrm{P}_{\mathrm{t}}\right)$ of the original price in the month that the $\$ 100$ price occurs. To estimate the curves represented in Figure 3 with regression the time variable, months since product introduction, is transformed using the natural log. $\mathrm{H}_{1}$ tests that prices fall in proportion to the natural logarithm of the number of months since the product was introduced. $\mathrm{H}_{2}$ tests that prices fall faster in a more competitive market for cameras introduced after the first product.

$\mathrm{H}_{1}$ : The price of a cellular trail camera declines in proportion to the natural log of time.

$\mathrm{H}_{2}$ : The price decline for cellular cameras introduced into a competitive market will be faster than in a single product market.

The third research hypothesis also relates to how prices change over time. In this case, examining the lowest available camera price, the price/performance frontier. There is a significant time trend for this case, but it was hypothesized that Google Trends data would quantify market interest in the product and so provide a better method to understand and forecast the price trend. The hypothesis is restricted to price, but examination of the data also illustrates that the increase in interest for cellular trail cameras has increased the availability of price and performance combinations. The idea of this hypothesis is that as market interest increases, scale economies come into play and competition increases, driving prices down.

$\mathrm{H}_{3}$ : Google Trends data is negatively correlated to the lowest available price for any cellular trail camera.

\section{RESULTS}

Table 1 presents two specifications of a regression equation testing $\mathrm{H}_{1}$ and $\mathrm{H}_{2}$. The first shows that with very high statistical significance the trail camera price as a proportion of the introductory price falls with the natural log of the number of months since the camera was introduced. $\mathrm{H}_{1}$ is accepted. The Competition Dummy variable in table 1 is valued at 0 for the first camera and 1 for all other cameras. The result indicates that the price decline accelerates for competitive cameras entering the market. $\mathrm{H}_{2}$ is accepted. 
The second equation with $\operatorname{Ln}\left(\mathrm{P}_{t} /\left(1-\mathrm{P}_{\mathrm{t}}\right)\right)$ as the dependent variable is an attempt to make a model specification that more closely represents the curves illustrated in Figure 3, which are similar to a logit model, logistic regression, or inverted S-curve. Left out of this equation is the feature that product prices sometimes increase during the product obsolescence stage. With only one product having entered this stage in this data sample, the sample size was too small to clearly identify this effect. The dependent variable transformation shown in table 1 for equation 2 is formulated like a logit model. The calculation for this dependent variable was modified somewhat to suite the transformation. The maximum price for each camera is rounded up to the nearest $\$ 50$ so that the denominator $\left(1-\mathrm{P}_{\mathrm{t}}\right)$ does not equal zero and explode the calculation. The variable transformation constrains results to be between zero and one, no negative prices. The second equation actually fits a little better at capturing the pattern as reflected in the higher R-Square and $\mathrm{F}$ values, favoring the logistic approach over the simple price ratio $\left(\mathrm{P}_{\mathrm{t}}\right)$.

Figure 4 illustrates the data used to test $\mathrm{H}_{3}$, that Google Trends is negatively correlated to the lowest available camera price. Table 2 provides several formulations of this test, estimated using regression analysis. All regression equations are highly significant with p-values (Equation Significance) close to 0, supporting the third research hypothesis. The table reports the results for seven equations using two different dependent variables and five different independent variables: 1) the raw value of the index, 2) a seasonally adjusted value of the index, 3) a one month lag of the seasonally adjusted index, 4) a six month lag of the seasonally adjusted index, 5) a twelve month lag of the seasonally adjusted index.



Figure 4: The lowest cellular camera price from August, 2010 to April, 2020 (left axis) compared to the Google Trends search index value and the seasonally adjusted Google Trends value (right axis). 


\section{Issues in Information Systems}

Volume 21, Issue 2, pp. 196-205, 2020

Seasonally adjusting the index removes the spike of increased interest in cameras during the fall when hunters are likely to be looking for new equipment and so improves the equation fit. The seasonally adjusted and lagged equations are all highly significant, indicating that the Google Trends data can be useful as a technology forecasting tool. Some improvement in the equation fit was achieved by exploring dependent variable transformations. For example, using the natural log of the camera price as the dependent variable raises the $\mathrm{F}$ value to 513 as reported near the bottom of table 2 for equation 6 . The last equation 7 in table 2 resulted in the highest $\mathrm{F}$ value of 571.7 when forecasting $\operatorname{Ln}\left(\right.$ Price $\left._{t}\right)$ twelve months ahead using the seasonally adjusted Google Trends Index. Although this equation has the beneficial property of constraining the price forecast to be above zero, the equation would likely need to be re-estimated as new data Google Trends data becomes available.

Table 2: Regression equations testing $\mathrm{H}_{3}$, using the lowest available camera price as the dependent variable, Price $_{t}$ for equations 1 through 5 and $\operatorname{Ln}\left(\right.$ Price $_{t}$ ) for equations 6 and 7 . The independent variables are variations of the Google Trends Search Index Value: raw index, seasonally adjusted index, and lagged index. $\quad \mathrm{N}=89$ $\mathrm{H}_{3}$ accepted.

\begin{tabular}{|c|c|c|c|c|c|}
\hline $\begin{array}{l}\text { Dependent Variable: } \text { Price }_{\mathrm{t}} \\
\text { The Independent Variable in } \\
\text { Each of Five Equation }\end{array}$ & R-Square & $\begin{array}{c}\mathbf{F} \\
(\mathrm{N}=89)\end{array}$ & $\begin{array}{c}\text { Equation } \\
\text { Significance }\end{array}$ & $\begin{array}{c}\text { Constant } \\
\text { (t, significance) }\end{array}$ & $\begin{array}{c}\text { Coefficient } \\
\text { (t, significance) }\end{array}$ \\
\hline 1. Google Trends Search Index & 0.550 & 107.7 & 0.000 & $\begin{array}{c}271.4 \\
(52.0, \quad 0.000)\end{array}$ & $\begin{array}{c}-2.16 \\
(-10.4,0.000)\end{array}$ \\
\hline $\begin{array}{l}\text { 2. Seasonally Adjusted Google } \\
\text { Trends Index }\end{array}$ & 0.782 & 315.4 & 0.000 & $\begin{array}{c}292.0 \\
(69.9, \quad 0.000)\end{array}$ & $\begin{array}{c}-4.29 \\
(-17.8, \quad 0.000)\end{array}$ \\
\hline $\begin{array}{l}\text { 3. Seasonally Adjusted Index, } \\
\text { One Month Lag }\end{array}$ & 0.778 & 305.3 & 0.000 & $\begin{array}{c}290.1 \\
(67.3, \quad 0.000)\end{array}$ & $\begin{array}{c}-4.36 \\
(-17.5, \quad 0.000)\end{array}$ \\
\hline $\begin{array}{l}\text { 4. Seasonally Adjusted Index, } \\
\text { Six Month Lag }\end{array}$ & 0.786 & 319.9 & 0.000 & $\begin{array}{c}296.8 \\
(65.7, \quad 0.000)\end{array}$ & $\begin{array}{c}-5.98 \\
(-17.9, \quad 0.000)\end{array}$ \\
\hline $\begin{array}{l}\text { 5. Seasonally Adjusted Index, } \\
\text { Twelve Month Lag }\end{array}$ & 0.743 & 248.3 & 0.000 & $\begin{array}{c}299.0 \\
(57.3, \quad 0.000)\end{array}$ & $\begin{array}{c}-7.52 \\
(-15.8, \quad 0.000)\end{array}$ \\
\hline $\begin{array}{l}\text { Dependent Variable: } \operatorname{Ln}\left(\text { Price }_{\mathrm{t}}\right) \\
\text { Independent Variable (as in } \\
\text { equations } 2 \text { and } 5 \text { above) }\end{array}$ & R-Square & $\begin{array}{c}\mathbf{F} \\
(\mathrm{N}=89)\end{array}$ & $\begin{array}{c}\text { Equation } \\
\text { Significance }\end{array}$ & $\begin{array}{c}\text { Constant } \\
(t, \text { significance) }\end{array}$ & $\begin{array}{c}\text { Coefficient } \\
(t, \text { significance })\end{array}$ \\
\hline $\begin{array}{l}\text { 6. Seasonally Adjusted } \\
\text { Google Trends Index }\end{array}$ & 0.818 & 513.0 & 0.000 & $\begin{array}{c}0.545 \\
(26.2,0.000)\end{array}$ & $\begin{array}{c}0.031 \\
(22.7,0.000)\end{array}$ \\
\hline $\begin{array}{l}\text { 7. Seasonally Adjusted Index, } \\
\text { Twelve Month Lag }\end{array}$ & 0.849 & 571.7 & 0.000 & $\begin{array}{c}0.514 \\
(23.3,0.000) \\
\end{array}$ & $\begin{array}{c}0.053 \\
(23.9,0.000)\end{array}$ \\
\hline
\end{tabular}

Google Trends is an index ranging from 0 to 100 , not a direct measure of search volume. If searches continue to increase for a few more months beyond what is depicted in Figure 4, the index will be reset to 100 for the peak of searches in the next fall related to deer hunting and all the historical data will be recalibrated. The estimated equations would no longer apply and would have to be re-estimated. As a practical matter, the statistics show a strong correlation between increased in interest in cellular cameras as measured by Google Trends and the market's response to provide cameras at lower prices. The project manager or systems analyst wanting information on price and performance trends may find that the data visualization presented in Figure 4 to be helpful and perhaps easier to apply than the equations for a feasibility analysis. Google Trends is clearly providing some useful information about the direction of the price/performance path.

\section{SUMMARY}

In the use case described earlier, cellular trail cameras were initially the desired equipment choice. They would have transmitted real-time images and reduced travel time required to manage the cameras. But because the project was operating without a budget, the cost of the data plan required for the cameras resulted in delaying their deployment. One innovation that has reduced the transmission cost involve using artificial intelligence to identify images of interest and transmitting only those. Other innovations in how new cellular cameras use the network and declining data plan prices have also made use of cellular trail cameras more attractive. A different decision about cellular cameras would be made if the use case project were started today. 


\section{Issues in Information Systems}

Volume 21, Issue 2, pp. 196-205, 2020

Loss of a key project sponsor is a common project management risk. Although there has been an increasing use of citizen science in wildlife and other research, as the use case shows there may be an associated increase in project risk. There may be less commitment to basic research goals.

This research provides evidence of the usefulness of the logistic regression or s-curve approach in identifying the pattern of price changes over a product life cycle. As might be expected, increased competition accelerates the rate of price declines. Over the past decade, Google Trends Keyword Search Index data has been shown to be useful in analyzing and forecasting for a variety of applications. This information can be helpful to project managers and systems analysts tasked with choosing equipment or a technology platform.

The information presented in the figures, showing declining prices with performance improvement and a growing interest in these cameras as identified with the Google Trends data, suggest that these product trends will continue. Some states are buying thousands of trail cameras for wildlife research and applications should increase given the data discussed here. Newly introduced IP cameras, which are also generating rapid increases in search interest as measured by Google Trends, are likely to follow a similar path as new satellite services open up internet access to remote areas not previously served by wireless services.

\section{REFERENCES}

Akyildiz, I. F., \& Kak, A. (2019). The internet of space things/CubeSats: A ubiquitous cyber-physical system for the connected world. Computer Networks, 150, 134-149.

Chumnumpan, P., \& Shi, X., (2019). Understanding new products’ market performance using Google Trends. Australasian Marketing Journal, 27(2), 91-103.

Duwe, D., Herrmann F., \& Spath, D. (2018). Forecasting the diffusion of product and technology innovations: Using Google Trends as an example. Portland International Conference on Management of Engineering and Technology (PICMET), Honolulu, HI, 1-7.

Elias, A.R., Golubovic, N., Krintz, C., \& Wolski, R. (2017). Where's the bear? - Automating wildlife image processing using IoT and edge cloud systems. IEEE/ACM Second International Conference on Internet-ofThings Design and Implementation (IoTDI), Pittsburgh, PA, 247-258.

Flamm, K. (2004). Moore's law and the economics of semiconductor price trends. International Journal of Technology, Policy and Management, 3(2), 151-170.

Gargallo, A., \& Gorriz, C.G. (2007). How to Measure Information and Communications Technology and Performance. Issues in Information Systems, 7(2), 89-96.

Gonzalez, L.F., Montes, G.A., Puig, E., Johnson, S., Mengersen, K., \& Gatson, J. (2016). Unmanned aerial vehicles (UAVs) and artificial intelligence revolutionizing wildlife monitoring and conservation. Sensors, 16(1). Available: https://www.mdpi.com/1424-8220/16/1/97/htm

Green, S.E., Rees, J.P., Stephens, P.A., Hill, R.A., \& Giordano, A.J. (2020). Innovations in Camera Trapping Technology and Approaches: The Integration of Citizen Science and Artificial Intelligence. Animals, 10(1). Available: https://www.mdpi.com/2076-2615/10/1/132

Gubbi, J., Buyya, R., Marusic, S., \& Palaniswami, M. (2013). Internet of things (IoT): A vision, architectural elements, and future directions. Future Generation Computer Systems, 29(7), 1645-1660.

Haleem, A., Mannan, B., Luthra, S., Kumar, S., \& Khurana, S. (2019). Technology forecasting (TF) and technology assessment (TA) methodologies: a conceptual review. Benchmarking: An International Journal, 26(1). Available: https://www.emerald.com/insight/content/doi/10.1108/BIJ-04-2018-0090/full/html 
Jun, S., Yoo, H.S., \& Choi, S. (2018). Ten years of research change using Google Trends: From the perspective of big data utilizations and applications. Technological Forecasting and Social Change, 130(May). 69-87.

Kirkpatrick, J.F., \& Turner, J.W. (2020). Wildlife contraception and political cuisinarts. In: Allen D., Howell, J. (eds). Groupthink in Science. Springer.

Long, R.A., MacKay, P., Ray, J., \& Zielinski, W. (2012). Noninvasive survey methods for carnivores. Island Press.

Manrique, P., Qi, H., Morgenstern, A., Velásquez, N., Lu, T., \& Johnson, N. (2013). Context matters: Improving the uses of big data for forecasting civil unrest: Emerging phenomena and big data. IEEE International Conference on Intelligence and Security Informatics, Seattle, WA, 169-172.

Nazir, S., Fairhurst, G., \& Verdicchio, F. (2017). WiSE - a satellite-based system for remote monitoring . International Journal of Satellite Communications and Networking, 35(3), 201-214.

Pagany, R., \& Dorner, W. (2019). Do crash barriers and fences have an impact on wildlife-vehicle collisions?-An artificial intelligence and GIS-based analysis. International Journal of Geo-Information, 8(66). Available: https://www.mdpi.com/2220-9964/8/2/66

Smith, A.C., Collins, K., and Mavris, D.N. (2017). Survey of technology forecasting techniques for complex systems. 58th AIAA/ASCE/AHS/ASC Structures, Structural Dynamics, and Materials Conference. January. Available: https://arc.aiaa.org/doi/abs/10.2514/6.2017-0974

Terada, K., Ohno, S., Mukai, H., Ishibashi, K., \& Yokotani, T. (2019). An ICN system focusing on distributed MQTT Brokers for IoT services. Electronics Communications and Computations (JAC-ECC) 7th International Japan-Africa Conference, 28-31.

Wang, M., \& Kettinger W.J. (1995). Projecting the growth of cellular communications. Communications of the ACM, 39(19), 119-122.

Webb, G.K. (1994). Integrated circuit pricing. Journal of High Technology Management Research, 5, 247-260.

Webb, G.K. (2009). Internet search statistics as a source of business intelligence: Searches on foreclosure as an estimate of actual home foreclosures. Issues in Information Systems, 10(2), 82 - 87.

Webb, G.K. (2010). Extrapolating the price to performance frontier for computer system components: Processing, storage, memory, and network interface. The Business Review, Cambridge, 18(1), 28 - 34.

Webb, G.K. (2017). Information acquisition and decision support for suburban deer management. Issues in Information System, 18(2), 158-170.

Wright, T.P. (1936). Factors affecting the cost of airplanes. Journal of the Aeronautical Sciences, 3(4), 122-128. 